\title{
Setting the urban development standards as the basis of ensuring eco-economic sustainability of construction
}

\author{
Ariadna Kirillova ${ }^{1, *}$ and Pavel Kostrikin ${ }^{1}$ \\ ${ }^{1}$ Moscow State University of Civil Engineering, Yaroslavskoe shosse, 26, 129337, Moscow, Russia
}

\begin{abstract}
The article highlights the main factors of eco-economic sustainability in construction as well as in choosing indicators of the minimum acceptable level of residential area provision with facilities and elements needed for shaping a full-fledged living environment and devising effective urban development solutions. At the present stage the key priorities in the development of quality urban environment are eco-economic aspects of residential development regulation and codification. The main purpose is creating optimal conditions for integrated development of residential areas and promoting (to some or other degree) the following priorities: the effectiveness of using the urban territory; shaping a salubrious living environment, including due to land improvement and landscaping, creating engineering and transport facilities, community infrastructure, household utilities and amenities, and providing free access to such facilities for low mobility groups; meeting environmental, sanitary and hygienic requirements, fire and pandemic safety requirements; meeting requirements for functional, spatial and planning organization of living environment, mitigation of environmental hazards and preventing the damage to lifesupport systems.
\end{abstract}

\section{Introduction}

The following principles of forming regional town-planning standards (RTPS) underlie the proposed model of codification:

- A high share of greenery planted in residential areas, shaping public gardens and boulevards inside different neighborhoods.

- Greened and landscaped private (courtyard) territories, free from motor traffic and serving as tranquil recreation grounds for local residents.

- Neighborhood pattern, implying clear separation between private (courtyards) and public (intra-neighborhood) territories as well as access for pedestrians to all elements of residential areas (children and sport playgrounds, dog-walking grounds, parking lots), along with daily and occasional household services (retail, educational, cultural and health institutions, social security offices, etc.).

\footnotetext{
* Corresponding author: angela-1309.m@yandex.ru
} 
Regional town-planning standards must set the totality of indicators defining the minimum acceptable level of provision with region-scale facilities as well as the maximum acceptable level of accessibility of such facilities - RTPS for residential areas (on the example of Moscow).

On this basis a new town-planning unit is introduced under the working name of "urban block" that includes residential buildings with daily services and amenities on lower floors as well as a private courtyard with greening, chill-out grounds and fire driveways, accessible mainly for the inhabitants of this particular urban block and closed for transit visits by the general public.

As per the RTPS project, the reference community is identified by the radius of access to elements of community-level codification of no more than 500 meters, on the neighborhood level - not more than 300 meters, and on the urban block level - not more than 100 meters, which guarantees accessibility in the system of residential formations and provision of local residents with community facilities and infrastructure.

As per MGSN 1.01-99 "Design Rules and Regulations of Urban Planning and Development in Moscow" [1-3] planting of greenery in a housing group (similar to a neighborhood in RTPS) must amount to 5.3 sq. $\mathrm{m}$ per capita, whereas in the developed RTPS an urban block must have at least $3 \mathrm{sq}$. $\mathrm{m}$ of green areas per capita plus $2.3 \mathrm{sq} . \mathrm{m}$ of greening per capita in public areas of the neighborhood. The idea is in redistribution, not a decrease: part of the greening is taken outside of the courtyard's precincts to shape public gardens and promenades as well as outdoor recreation grounds.

It is assumed that the planning arrangement of neighborhoods and urban blocks allows the erection of residential buildings with an integrated development front, more traditional for a city than chaotically placed volumes. On lower floors along the street front and intraneighborhood driveways, the standards anticipate the retail function and services, which must saturate the environment of residential streets.

In the proposed model of town-planning codification a more rational plan of intraneighborhood territories is suggested, which must enable orderly driveways and parking lots and thus preclusion of chaotic parking in courtyards. Green areas in communities (boulevards, public gardens, recreational grounds) must also be used rationally, with landscaped recreation areas to replace haphazard and practically unused "green patches" [4].

Clear separation of private and public territories within the neighborhood bounds is also anticipated. Private territories are earmarked within the urban block and represent greened landscaped courtyards with playgrounds for kids and chill-out zones; such territories are totally cleared of motor transport (save for special vehicles).

Public territories are earmarked within the neighborhood and include driveways, parking lots, public gardens and boulevards. Mainly utilitarian public territories (with driveways, parking lots, utility sites) must be separated from green pedestrian areas. Codification objects are clearly pegged to the communication system comprising intra-neighborhood driveways and a local street and road grid ensuring the permeability of residential areas and normal access to all lifestyle facilities and elements of the living environment $[5,6]$.

\section{Object of the study}

As a reference object for the given development we use the analytic data of foreign experience in residential development regulation and codification, allowing to draw the following conclusions.

- The planning of residential development both abroad and in Russia is based on functional zoning that enables the placement of certain functions in different parts of the city; the parameters on types of use are then regulated down to the neighborhood and plot of land 
(NYC), with specific parcels earmarked in any predominantly non-residential zone (London).

- Regulation and codification are normally provided at the municipal level for a specific urban settlement, with special emphasis placed on checking the abidance by the rules.

- Reflected in foreign residential development regulations is a broad range of issues which can conventionally be represented as three blocks shown in Table 1.

Table 1. Areas of residential development regulation and codification.

\begin{tabular}{|l|l|}
\hline Block I & Regulation of urban planning and development parameters \\
\hline Block II & Regulation of development density/intensity \\
\hline Block III & $\begin{array}{l}\text { Regulation of residential area elements (in particular, greenery and car spaces) } \\
\text { to be provided }\end{array}$ \\
\hline
\end{tabular}

Let's characterize the blocks described in Table 1.

Block I: Regulation of urban planning and development parameters

The regulation includes such parameters as placing a building on a plot of land, maximum size (dimensions), setback from the red lines (or their absence), width of streets, extension of facades, spacing of buildings, maximum height of development. In most cities of Europe and North America the regulation enforces the neighborhood pattern of development $[7,8]$.

The regulation of urban planning and development parameters reflects:

- the required nature of urban planning and development;

- the conditions for deviation from the set parameters, e.g. taller developments (Singapore);

- taking into account the landscape specifics and the context of surrounding development;

- preventing the deterioration of conditions for the surrounding development

- distinguishing characteristics of an urban settlement or its part.

Block II: Regulation of development density/intensity

Both the development and population density as well as the density of residential units and living premises can be a regulated parameter of intensity (density).

At the level of large residential entities (analogues of districts and communities) an important regulator for the designer is carrying amounts, whereby shares for placement of roads, greening and development proper are assigned.

The regulation of development intensity (density) ensures [9]:

- taking the specifics of the urban settlement (its size, significance) into account;

- diversification of development density, depending on the parcel location in the city structure (Perth, Australia);

- effectiveness of using urban areas due to the setting of lower density limits;

- favorable living environment, exclusion of cramped areas by setting upper density limits;

- enabling the redistribution of intensity between neighboring land parcels.

Block III: Regulation of provision with residential area elements

Greening is among the regulated elements of residential areas almost in all countries, with the greening of roofs and balconies encouraged in a number of cases (London, big cities of Australia). In some countries children and sport playgrounds (Germany) as well as recreation grounds are also among the regulated elements. Most standards and regulations reflect parking space requirements for residents and non-residential buildings. In some of the world capitals the number of private automobiles is limited (Singapore).

The regulation of provision with residential area elements must guarantee the creation of a comfortable living environment, environmentally benign living conditions, providing 
requisite amenities for local residents within the confines of residential areas (i.e. easy of access for pedestrians).

The RTPS requirements specified in the Town-Planning Code of Russia include only the third block, whereas the key development parameters (Block I) and its intensity (Block II) are prescribed, respectively, in the territorial planning documents (general plan) and townplanning zoning (land use and development rules). The regulatory requirements "SP 42.13330.2011. Urban Development. Town-planning and development of urban and rural settlements" $[10,11]$.

Thus analyzing the foreign experience can provide material not so much for the development of town-planning design standards, as rather for possible improvement of the regulatory framework for the development and adjustment of general and zoning plans.

\section{Basic assumptions, method and algorithm}

The codification of urban development as the basis of ensuring the eco-economic sustainability of development activities creates conditions for the regulation of reproduction processes (development and functionality), when creating residential development, utility infrastructure as well as social, domestic and cultural facilities. The integrated development of urban territories has a considerable environmental impact upon the process of real estate construction and operation. The impact intensity is a function of the resource intensity of construction operations, the need for various resources, pollution of the atmospheric air, water arteries, disfigurement of landscapes, etc. [13, 14]. Under these conditions it is at the stage of codification and design that methods of ensuring the eco-economic sustainability of construction activities are laid, including methods of legal regulation, based on:

- shaping regional town-planning design standards which ensure the safety of ecosystems in the best possible way;

- eco-management in the construction industry, oriented towards the development of environmentally neutral sectors of residential development (household services, educational institutions, etc.);

- instruments of environmental regulation of implementing nature conservation investments and environmental system of consumer predilections;

- mechanisms of eco-economic interaction between economic entities in the construction and operation of facilities;

- development of innovative technologies and the use of renewable energy sources.

In general, the eco-economic sustainability of construction model $\mathbf{Y}$ may have the following interpretation:

$$
\mathrm{Y}=\mathrm{F}(\mathrm{RN}, \mathrm{PO}, \mathrm{NP}, \mathrm{CK}, \mathrm{KM}, \mathrm{IT}, \mathrm{UE}, \mathrm{BOC}, \mathrm{U}, \mathrm{RI}, \mathrm{PI}, \mathrm{BO} \mathrm{IC}, \mathrm{EP})
$$

Where:

$\mathrm{RN}$ - regional town-planning design standards;

$\mathrm{PO}$ - eco-legal support of construction;

$\mathrm{NP}$ - the standards and rules of design of investment-construction projects and building operations;

CK - construction control (monitoring);

$\mathrm{KM}$ - quality of materials and building products;

IT - innovative technologies;

UE - operational environment;

BOC - environmental impact;

$\mathrm{U}$ - risks of damaging the environment;

RI - profitability of projects (return on investments);

PI - nature conservation investments; 
$\mathrm{BO}$ - landscaping and planting of greenery;

IC - utility systems;

$\mathrm{EP}$ - environmental education.

Setting the priorities of construction activities while taking the environmental imperative into account preconditions the need for compromise and balanced solution of the problems with growing construction volumes as well as the use of innovations, renewable sources of energy and the habitable environment preservation methods.

\section{Conclusions}

Analyzing the foreign experience in the codification and regulation of urban design solutions shows that regulations are set specifically for every city and normally for each land parcel, and contain indicators similar to the ones found in the national zoning rules. These indicators regulate the intensity of using residential areas and the type of development, depending on their positioning in the city structure. In some cases, the standards of providing the living environment with car spaces, green spots, recreation areas and playgrounds are also envisaged. A major emphasis is also placed on the privacy of residential spaces and harmonizing them with the historic development.

The standards and regulations in developed markets are more considerate about land and property titles than their Russian prototypes, as the former are oriented towards the homestead. On the other hand, they contain fewer guarantees of infrastructure creation (community infrastructure, in the first place), whenever residential neighborhoods are formed. Thus it can be stated that the regulation proposed in the given article provides for comfortable and favorable living conditions in line with the federal urban planning and sanitary-hygienic requirements, including:

- provision of residents with socially significant facilities (including schools and daycare centers) with standard accessibility;

- shaping landscaped and greened residential courtyards free from motor transport (private greening);

- shaping full-fledged recreational greened areas with all essential infrastructure (sport playgrounds, recreation grounds) inside the neighborhood (public greening) and community (greened public spaces);

- accommodation of retail facilities and services on lower floors, to allow for a functionally saturated environment of residential streets and intra-neighborhood driveways;

- elaboration upon the profiles of streets and intra-neighborhood driveways, allowing for the comfort of pedestrians;

- planning of neighborhoods and urban blocks, to ensure an integrated development front, traditional for cityscapes.

\section{References}

1. A. Shlafman, A. Mottayeva, Online magazine of science 6 (19), 114 (2013)

2. T. Meshcheryakova, Economy and entrepreneurship 8 (37), 334-336 (2013)

3. L. Vlasenkov, Matec web of conferences 106, 01009 (2017)

4. I. Prydko, International Journal of Applied Engineering Research 21, 42147-42152 (2015)

5. T.Y. Ovsiannikova, M.N. Nikolaenko, IOP Conf. Series: Materials Science and Engineering 71, 012051 (2015) DOI: 10.1088/1757-899X/71/1/012051

6. T. Iskanderov, M. Kuchkarova, Hygiene and Sanitary 4, 31 (2004) 
7. J. Ćetković, M. Knežević, N. Ivanišević, S. Rutešić, Central European Journal of Spatial and Landscape Planning, Terra Spectra Stu 1/2010, 47-55 (2010) ISSN 1338-0370

8. Zoning handbook (New York Department of City Planning, 2011)

9. E. Sazonov, V.V. Smolyaninov, VGASU Academic Herald. Construction and Architecture 3(19), 123 (2010)

10. L. Avdotyin, Urban Design (Moscow, Stroyizdat, 1989)

11. N. Brookes, N. Ivanišević, A. Lukasiewicz, T. Sainati, C. lo Storto, Special Purpose Entities in Megaprojects, Transport and Urban Development, Action megaproject TU 1003 (University of Leeds, 2015) ISBN 978-0-9576805-3-1

12. M. Petronijević, A. Nikolić, M. Mikić, N. Ivanišević, Ahp Based Contractor Selection Procedure For Highway Infrastructure Projects In Serbia, 12th International Conference Organization, Technology and Management in Construction OTMC 2015, 206-214 (2015) ISBN 978-953-7686-06-2 